\title{
Mariano Granados de Aguirre y la cobertura legal del traslado del «Oro de Moscú»
}

\author{
Raul C. Cancio \\ Doctor en Derecho. Letrado del Tribunal Supremo
Mariano Granados de Aguirre and the legal coverage of the transfer of «Moscow Gold»

\begin{abstract}
RESUMEN
La decisión gubernamental de trasladar parte de las reservas de oro depositadas en el Banco de España a la Unión Soviética durante el otoño de 1936 es un episodio histórico que demanda, desde hace muchos años, una aproximación lo más aséptica posible habida cuenta de la nociva manipulación del que ha sido objeto. Desde esta permisa, el presente trabajo pretende analizar, desde un prisma estrictamente jurídico-técnico, la adecuación a Derecho de la decisión gubernamental, tanto desde el punto vista formal como sustantivo, ello sin perjuicio de su ineludible encuadramiento histórico temporal. Ese análisis de los parámetros jurídico legales de las disposiciones habilitantes del traslado, nos permitirá además conocer con alguna profundidad

la peripecia vital del representante del poder judicial en esa operación, el magistrado del Tribunal Supremo Mariano

Granados de Aguirre, figura arquetípica del republicanismo español ilustrado de la Guerra y del exilio.

PALABRAS CLAVE: Guerra civil. Exilio. Oro. Tribunal Supremo. Poder Judicial. Unión Soviética.
\end{abstract}

\begin{abstract}
The government's decision to relocate part of its gold reserves deposited in the Bank of Spain to the Soviet Union during the fall of 1936 is a historical episode that demand for many years, an approximation as aseptic as possible given the harmful manipulation which has been subjected. Since these permits, this paper aims to analyze, from a purely legal-technical lens, matching the government's decision law, both formally as a noun, without prejudice to its inescapable historical framework temporary. That legal analysis of the legal parameters of the enabling provisions of the shipment, will also allow us to know in some depth the vital vicissitudes of the representative of the judiciary in that process, the Supreme Court Justice Mariano Granados de Aguirre, Spanish republicanism archetypal figure illustrated War and exile.
\end{abstract}

\section{KEYWORDS:}

Civil War. Exile. Gold. Supreme Court. Judiciary. Sovietic Union. 
Al rincón donde el Cielo del destino me espera

Vienes tú, patria mía, con tu llanto y mi cruz.

España va en mi pecho, libre, próspera, entera, y no podréis robármela, ladrones de la luz.

Canto a España, Tránsito (1944)

Mariano Granados

Fue en España donde los hombres aprendieron que es posible tener razón... y aún así, sufrir la derrota.

Juan Negrín

Los buscadores de oro cavan mucho y hallan poco.

Heráclito de Éfeso

\section{INTRODUCCIÓN}

La historiografía en torno al traslado de las reservas de oro del Banco de España a la Unión Soviética (en puridad, las tres cuartas partes, la otra fue a Francia) en el mes de octubre de 1936 ofrece tal amplitud de perspectivas que resultaría extraordinariamente osado pretender a través de estas breves líneas introducir elementos novedosos a una cuestión insistimos, exhaustivamente analizada1. Ahora bien, ello no es óbice para descubrir como alrededor de la cuestión central, se mantienen aún en la penumbra personas, acontecimientos y datos que si bien tangenciales, no han sido suficientemente revelados y que demandan, por el interés que encierran y por la relevancia de sus protagonistas, una particular atención. Este el caso precisamente de la intervención del poder judicial en la custodia y traslado del preciado material, personificada en la figura del magistrado, escritor, humorista y poeta Mariano Granados de Aguirre, un personaje — como tantos otrosinjustamente postergado de las crónicas historiográficas, y representante cualificado de ese perfil de hombre con un acentuado sentido de lo español, republicano cabal e ilustrado, creyente, probo y riguroso en el ejercicio de su profesión y con un

1 HOWSON, G.: Armas para España. La historia no contada de la guerra civil española. Barcelona, Península, 2000; KOWALSKY, D.: La Unión Soviética y la guerra civil española: una revisión crítica. Barcelona, Crítica, 2003; MARTín ACEÑA, P.: El Oro de Moscú y el Oro de Berlín. Madrid, Taurus, 2001; MIRALLES, R.: Juan Negrín: la República en guerra. Madrid, Temas de Hoy, 2003; VIÑAS, Á.: El oro de Moscú. Barcelona, Grijalbo, 1979; La soledad de la República: el abandono de las democracias y el viraje hacia la Unión Soviética. Barcelona, Crítica, 2006 y El escudo de la República. El oro de España, la apuesta soviética y los hechos de mayo de 1937, Barcelona, Crítica, 2007. 
acendrado sentido de la lealtad, entre los que desde luego podríamos incluir a figuras como el general Rojo, el doctor Bastos Ansart, el también magistrado Mariano Gómez o el coronel Joaquín Pérez-Salas².

Para abordar la cuestión anunciada, se principiará por verificar la cobertura legal del tantas veces repetido traslado, para continuar examinando la configuración del poder judicial en la España del otoño de 1936. A partir de entonces se profundizará en el perfil de Mariano Granados como representante del referido poder constitucional en la custodia y remisión del oro, terminando con una breve reseña de las operaciones logísticas que se llevaron a cabo en la Estación Naval de La Algameca y que culminaron en el Depósito de Metales Preciosos del Comisariado del Pueblo de Finanzas (Гохран/Gokhran).

\section{COBERTURA LEGAL DEL TRASLADO DEL ORO}

Antes de cualquier consideración, y dejando al margen los innumerables juicios de valor vertidos sobre el tema, muchos de ellos burdamente sesgados y de inequívoca tendenciosidad, así como la instrumentalización, por unos y otros, del tantas veces cacareado «expolio del oro español», se impone comprobar, desde parámetros exclusivamente jurídicos, si la decisión del ejecutivo de Largo Caballero de trasladar el oro tuvo el conveniente respaldo legal y, en su caso, cual fue el soporte normativo sobre el que se articuló la decisión gubernativa, sobre la que también deberemos detenernos brevemente.

En este sentido, resulta incontrovertible - muy a pesar de la opinión de dos de los consejeros del Banco de España que en ese momento se opusieron, MartínezFresneda Jouvé y Álvarez Guerra y, de la por lo demás lógica alarma del bando sedicioso ${ }^{3}$ — , que el Gabinete disponía del correspondiente amparo legal para to-

2 Sobre todos ellos hay literatura de altísima calidad, que pone negro sobre blanco todas la cualidades arriba referidas. En este sentido vid. ROJO, J. A.: Vicente Rojo. Retrato de un general republicano.Tusquets, Barcelona, 2006; BENEITO LLORIS, Á.: El Hospital Sueco Noruego de Alcoi durante la Guerra Civil Española. Alfa Ediciones Gráficas, Alcoi, 2004; MIRALLES SANGRO, P. P.: Al servicio de la Justicia y de la República. Mariano Gómez (1883-1951) Presidente del Tribunal Supremo. Dilex, Madrid, 2010 y LÓPEZ ROMERO, L: Joaquín Pérez Salas: (segunda época 1937-1938). Ayuntamiento de Pozoblanco, Pozoblanco, 2006.

3 Decreto no 36: «(...) Se declara delito de traición el cometido con las exportaciones de oro del banco de España que se hayan efectuado hasta la fecha y que se realicen en lo sucesivo, así como las que pudieran existir procedentes de la Banca privada o de los particulares. Los autores de esas expoliaciones y cuantas personas hayan intervenido en esas operaciones, serán juzgados, en su día, por procedimiento sumarísimo, como reos de un delito que tan grave daño ha inferido y puede inferir a la Nación española»

Decreto no 65: «Interesa a esta Junta, en el orden moral, destacar, una vez más, el escándalo que ante la conciencia universal ha producido la salida de oro del Banco de España, decretada por el mal llamado Gobierno de Madrid. Pero la incumbe más principalmente señalar las consecuencias de esas operaciones en el terreno jurídico, porque efectuadas con abierta infracción de preceptos fundamentales de la vigente Ley de Ordenación Bancaria, es evidente conducen por su manifiesta ilegalidad a la conclusión inexcusable de su nulidad, que ha de alcanzar en sus efectos civiles a cuantas personas nacionales o extranjeras hayan participado en ellas, con independencia de la responsabilidad criminal, ya regulada en otro Decreto. Y es lógico complemento de esta declaración, el prevenir los daños que se irroguen, con 
mar la decisión que tomó, desde el momento en que la Ley de Ordenación Bancaria (LOB) vigente por entonces y aprobada por Real Decreto Ley 190/1927, de 24 de enero (Gaceta de Madrid no 28, de 28 de enero de 1927), reformada en su artículo $1^{\circ}$ por Ley de 26 de noviembre de 1931 (Gaceta de Madrid nํ31, de 27 de noviembre de 1931), contemplaba en el citado artículo 1ㅇ las condiciones para la movilización por parte del Banco de las reservas, estableciendo en su Base Segunda la preceptiva autorización del Consejo de Ministros para todo lo concerniente a la disminución de las existencias de oro amonedado y en barras. Por otra parte, esta disposición se complementaba con la Base Séptima del mismo precepto, que establecía:

«En el caso de que el Gobierno, con arreglo a las facultades que las leyes le conceden por espontáneo y singular acuerdo o en virtud de concierto internacional en el que participe España, decida ejercer una acción interventora en el cambio internacional y en la regularidad del mercado monetario, el Banco de España, si esta intervención se efectúa por su mediación o con su intervención, participará en la misma proporción que el Estado en las operaciones a que dicha política de lugar. El oro del Banco que se aplique a la realización de dicha acción interventora será siempre computado íntegramente como reserva, a los efectos de la base segunda, mientras continúe siendo de su exclusiva propiedad, incluso en el caso de que los dichos fondos fuesen situados en poder de los corresponsales del Banco en el extranjero, sin que obste para situarlos con tal fin la limitación consignada en el párrafo penúltimo de la base segunda (...) En caso de que la acción interventora en el cambio internacional y en la regularidad del mercado monetario no se confíe a un órgano distinto del Banco de España y sin su intervención, el Gobierno concertará con éste la participación que al Banco corresponda por el concurso que preste al desarrollo de dicha acción interventora. En este caso, si el estado acordara ulteriormente la cesación de la acción interventora o el auxilio en ella del Banco, habrá de devolverle en oro las cantidades que en este metal hubiera aportado el Banco para realizarla. El plazo de la devolución no podrá exceder de seis meses, a contar de la fecha en que cesara la acción interventora o la participación del Banco en la misma».

Con el referido sostén normativo, debe concluirse por tanto que las decisiones adoptadas por el Consejo de Ministros en relación con la disponibilidad y traslado de las reservas aurificas del Banco de España fueron adoptadas conforme a De-

medidas de caución, que han de adoptarse con la urgencia que la defensa de los intereses nacionales exige.

En su virtud, como Presidente de la Junta de Defensa Nacional, y de acuerdo con ella, vengo en decretar lo siguiente:

Artículo primero. Se declaran nulas todas las operaciones que se hayan verificado o se verifiquen con la garantía del oro extraído del Banco de España, a partir del dieciocho de Julio último, y en su día se ejercitarán cuantas acciones correspondan en Derecho, para el rescate del oro referido, sea cual fuere el lugar en que se halle.

Artículo segundo. Sin perjuicio de la responsabilidad criminal definida en el Decreto número 36, los valores, créditos, derechos y bienes de todas clase que posean en España las personas o entidades nacionales o extranjeras que hayan intervenido o intervengan directa o indirectamente en las operaciones a que se contrae el artículo precedente, serán inmediatamente embargados, a fin de asegurar las responsabilidades de cualquier especie que se deriven de tales actos. Dado en Burgos a 25 de agosto de 1936. 
recho y de acuerdo con la legalidad vigente en materia monetaria. Cuestión distinta, lógicamente, es el juicio crítico que pudiere merecer el destino de esas reservas, extremo que en todo caso respondía a una decisión estrictamente política y no evaluable jurídicamente.

De esta forma, tanto el Decreto reservado de 30 de agosto de 1936, en el que se autorizaba al ministro de Hacienda para disponer que por el Centro Oficial de Contratación de Moneda (COCM) se situara en el extranjero en una o varias remesas y por cuenta del Tesoro, la cantidad de francos franceses que se estimase adecuada para atender los gastos que las necesidades de la campaña impongan, como el que de manera particular autorizó el traslado del metal, de 13 de septiembre de 1936, que estipulaba:

\section{«Excmo. Sr:}

Por su excelencia el presidente de la República, y con fecha 13 del actual, ha sido firmado el siguiente decreto reservado: La anormalidad que en el país ha producido la sublevación militar aconseja al Gobierno adoptar aquellas medidas precautorias que considere necesarias para mejor salvaguardar las reservas metálicas del Banco de España, base del crédito público. La índole misma de la medida y la razón de su adopción exigen que este acuerdo permanezca reservado. Fundado en tales consideraciones, de acuerdo con el Consejo de Ministros, y a propuesta del de Hacienda, vengo en disponer, con carácter reservado, lo siguiente:

- Art. 1: Se autoriza al Ministro de Hacienda para que en el momento que lo considere oportuno ordene el transporte, con las mayores garantías, al lugar que estime de más seguridad, de las existencias que en oro, plata y billetes hubiera en aquel momento en el establecimiento central del Banco de España.

- Art. 2o: El Gobierno dará cuenta en su día a las Cortes de este decreto.

como finalmente, los dos datados en 6 de octubre del mismo año, en los que, respectivamente, se modificaba el artículo 3 del citado Decreto de 30 de agosto, en el sentido de ampliar la disponibilidad de los créditos afectos a otros Departamentos y, en segundo lugar, se atribuía directamente al Banco de España las facultades concedidas al COCM, todos ellos, como decimos, se ajustan tanto formal como sustancialmente, a las previsiones legislativas vigentes.

\section{EL PODER JUDICIAL EN SEPTIEMBRE DE 1936}

Antes incluso de la promulgación de la Constitución de 1931, el advenimiento del régimen republicano el 14 de abril de 1931 vino acompañado, como no podía 
ser de otra forma, de un furor legislativo 4 que lógicamente incidió de manera notable en el ámbito de la administración de justicia. En los gobiernos republicanos primó más la republicanización de las instituciones judiciales que su independencia, la cual ni se negaba ni se menospreciaba pero se postergaba para un momento posterior donde el régimen republicano estuviese más consolidado ${ }^{5}$. En este sentido, y para evitar que la judicatura, trufada en su alta magistratura de elementos conservadores, se constituyese en un nuevo enemigo de la recién estrenada República, se incrementaron los honorarios de los magistrados, se reformó el Tribunal Supremo, se depuró el escalafón judicial, etc. Como tendremos ocasión de comprobar, con el alzamiento rebelde de 1936, el poder judicial se convirtió irremediablemente en un instrumento indispensable de la causa política. El mecanismo empleado por el ejecutivo republicano para acometer dicha remodelación fue esencialmente y de una parte, la jubilación —sistema que se usará con profusión en las purgas posteriores al alzamiento-, y de otra la promoción para la alta magistratura de profesionales de otras parcelas del derecho ${ }^{6}$.

El vértice de la organización judicial lo ocupaba el presidente del Tribunal Supremo, cuya novedosa designación ${ }^{7}$ correspondía al Jefe del Estado, a propuesta de una Asamblea ${ }^{8}$. La figura del presidente del Alto Tribunal diseñada por la Constitución de 1931 modificaba de forma radical la concepción que de la misma se tenía hasta entonces y no sólo en lo tocante a las peculiaridades de su elección, sino en los amplios poderes que le eran atribuidos, no sólo de naturaleza jurisdiccional, sino gubernativos y de carácter «político», de manera que se convirtiera, en palabras del diputado Marín Lázaro «en una magistratura constitucional que por sí sola significa una proclamación de la independencia del poder judicial»». Repárese que además de las facultades propias, tenía las de preparar y proponer al ministro de justicia y a la comisión parlamentaria, leyes de reforma judicial y de los códigos de procedimiento, lo que infundó grave temor al entonces presidente Diego Medi-

4 Véase el Decreto de 15 de abril de 1931 (Gaceta no 107, de 17 de abril de 1931) por el que se ordenaba a cada departamento ministerial la revisión, antes del 31 de mayo, de toda la normativa en vigor.

5 MARZAL RODRÍGUEZ, P.: «La alta magistratura en el reciente constitucionalismo español: paralelismos y discrepancias», en Constitución española. XXV Aniversario, Generalitat Valenciana, Valencia 2004, p. 108.

6 Sobre el escenario jurisdiccional durante la Guerra Civil, así como la política depurativa en ese periodo, puede consultarse CANCIO FERNÁNDEZ, R. C.: Guerra civil y tribunales: de los jurados populares a la justicia franquista (1936-1939), Universidad de Extremadura, Cáceres, 2007.

7 La Ley de 8 de octubre de 1932 (Gaceta de Madrid nº 394, de 18 de octubre de 1932) regulaba tal designación.

8 Constituida por los presidentes de Sala del Tribunal Supremo; los miembros del Consejo Fiscal; los presidentes de las audiencias territoriales; los jueces de Primera Instancia e Instrucción que ocupen los diez primeros números de su escalafón en el momento de hacerse la convocatoria de la Asamblea; quince Diputados a Cortes designados por el Parlamento; los Decanos de los Colegios de Abogados de las capitales de provincias de más de 50.000 habitantes; los decanos de las Facultades de Derecho y los presidentes de las Academias Nacionales de Ciencias Morales y Jurisprudencia.

9 MARZAL RODRÍGUEZ, P.: op. cit., p. 123. 
na ${ }^{10}$, a la luz de sus ausencias en la Comisión Jurídica ${ }^{11}$ y la propuesta asimismo al ministro, previo acuerdo de la Sala de Gobierno y los asesores jurídicos los ascensos y traslados de jueces, magistrados y funcionarios fiscales.

El Tribunal Supremo, merced al ya citado Decreto de 6 de mayo de $1931^{12}$, ratificado después por la Ley de 30 de diciembre ${ }^{13}$, se estructuraba en torno a cinco Salas, cada una de ellas integrada por una sola Sección: Primera, de lo Civil, constituida por un presidente y nueve magistrados. Segunda, de lo Criminal, formada por un presidente y siete magistrados. Tercera y Cuarta (que vino a sustituir la Sección Segunda de la Sala Tercera), de los Contencioso-Administrativo, con dos presidentes y diez magistrados y Quinta, de Cuestiones de Derecho Social, constituida por un presidente y cuatro magistrados y que entendía de los recursos de casación interpuestos por infracción de ley y quebrantamiento de forma contra la resoluciones de los Tribunales Industriales y Comisiones mixtas de trabajo. Finalmente, y con carácter transitorio, se creó por la Ley de 26 de julio de 1935 y Decreto de 8 de agosto, la Sala Séptima, asimismo de lo Contencioso-Administrativo para conocer de asuntos relacionados con la administración local. A la Sala de Gobierno se le reconoce la facultad de modificar la composición de las Salas cuando ello sea aconsejable por la competencia y especialidad de los magistrados y a fin de alcanzar un rendimiento superior en el servicio.

En el orden contencioso-administrativo, los únicos órganos jurisdiccionales con competencia en esta materia, amén de las Salas Tercera y Cuarta, fueron los Tribunales Provinciales de lo Contencioso.

Como manifestación de «justicia regional», el único Tribunal de estas características fue el Tribunal de Cassació de Cataluña, cuyo primer presidente fue el jurista Josep Andreu Abelló, instaurado por la Ley Regional de 10 de marzo de 1934, en cuyo artículo 11 se le reconocía competencia para el conocimiento de aquellos asuntos que versaran sobre materias civiles y administrativas cuya legislación exclusiva estuviere atribuida a Cataluña y sobre el que profundizaremos más adelante.

10 En el discurso de apertura de Tribunales del año 1935, Diego Medina señalaba al respecto «debemos temer por la responsabilidad que lleva aparejada para el cargo en lo sucesivo; porque de hoy más el Presidente tendrá que poseer conocimientos acabados y completos que son necesarios para resolver cotidianamente cuestiones de derecho procesal y orgánico, con la urgente premura que demandan los requerimientos de las personas y organismos del Estado que estamos obligados a asesorar, así en la esfera doctrinal como en el terreno práctico de su obligado desenvolvimiento, sobre cuantas leyes de reforma judicial y de los Códigos de procedimiento que surjan de la iniciativa del Gobierno o de la Comisión parlamentaria de justicia, cuidando de que no sea tentativas sin fortuna o desgraciadas que, careciendo de eficacia para la recta, pronta y económica administración de justicia, puedan contribuir a desprestigiar el régimen judicial, tan necesitado siempre de no contra con fracasos las etapas de su vida pública».

11 MARZAL RODRÍGUEZ, P.: op. cit., p. 131.

12 Gaceta de Madrid no 127, de 7 de mayo de 1931.

13 Gaceta de Madrid n요 8, de 8 de enero de 1932. 
Uno de los principales efectos de la rebelión militar de julio de 1936 fue indiscutiblemente la voladura de la organización administrativa central en todas sus esferas. El vacío dejado por aquélla fue cubierto, de forma más o menos autónoma, por las organizaciones revolucionarias conectadas con el Frente Popular, tanto en el plano local, provincial como en el regional. Durante el mes siguiente al alzamiento de los insurgentes, surgieron de forma simultánea en todo el territorio controlado por las fuerzas leales al gobierno de la República «comités revolucionarios de justicia», «tribunales revolucionarios» y «comités de salud pública», que administraban justicia aplicando sus propios códigos y a través de las estructuras propias de las organizaciones revolucionarias, lo que marginó definitivamente la actividad de la justicia "ordinaria» de juzgados y tribunales. Este colapso ${ }^{14}$ no fue tampoco subsanado a través de la actividad del Ministerio de Justicia, incapaz de responder a esta situación, limitándose a dictar algunos decretos «ante las circunstancias en que se hallaba el país» de escasa repercusión en el funcionamiento de los órganos jurisdiccionales.

El caos reinante en la retaguardia republicana, donde la represión sistemática mediante los «paseos», «sacas» y ejecuciones arbitrarias resultaba incontrolable, obligó a las fuerzas revolucionarias a la constitución de embrionarios órganos de administración de justicia como los que hemos referido antes. No obstante del servicio que éstos tribunales populares pudieron prestar ${ }^{15}$, salvando no pocas vidas de una muerte segura a manos de los elementos radicales, lo cierto es que eran muchas las carencias de las que adolecían, por lo que, bien por iniciativa de las propias organizaciones revolucionarias — Valencia y Barcelona-, bien a instancia de los gobiernos regionales - Cataluña y Asturias - o bien por mandato del propio gobierno central, se hizo sentir la necesidad de dotar a esos «tribunales revolucionarios» de ciertas formalidades legales, de manera que sus resoluciones, acuerdos y fallos se emitieran revestidos de un mínimo grado de legitimidad.

La reorganización por parte del gobierno de la República del sistema judicial tras la sublevación militar y por ende, la inaplicabilidad de facto del Título VII de la Constitución debe atribuírsele fundamentalmente al ministro sin cartera Manuel de Irujo (y más tarde al también ministro de Justicia García Oliver) y se inicia cuando el 16 de agosto se declaró cesantes a todos los jueces municipales y se decretó que «quiénes lo desempeñen en lo sucesivo ofrecerán las mayores garantías de una actuación limpiamente republicana». Hasta aquel 16 de agosto, y al margen de la disposición referida más arriba, lo cierto es que el gobierno de Giral, integrado por republicanos moderados ${ }^{16}$ y quizá arrastrado por una excesiva prudencia y una

14 SÁNCHEZ RECIO, G.: «Justicia ordinaria y Justicia popular durante la guerra civil» en Justicia en Guerra. Jornadas sobre la Administración de Justicia durante la Guerra Civil Española: Instituciones y fuentes documentales, Ministerio de Cultura, Madrid, 1990. 96.

15 ZUGAZAGOITIA, J.: Guerra y vicisitudes de los españoles, Tusquets Editores, Barcelona, 2001, p.

16 Barcia Trelles, Blasco Garzón, Ruiz Funes, Giner de los Ríos, Álvarez Buylla, Barnés Salinas o Ramos Ramos.... 
candorosa esperanza en el normal funcionamiento de las instituciones preexistentes, a tres semanas del inicio de la rebelión, aun no había tomado ninguna medida efectiva para reestablecer el funcionamiento de la justicia ordinaria del territorio leal, y ello a pesar de las enormes presiones a las que estaba sometido desde todos los sectores sociales, especialmente de la prensa escrita, cuyas demandas de una justicia revolucionaria ocupaban de forma invariable las primeras planas de los rotativos un día si y el otro también ${ }^{17}$. En esas primeras semanas de agosto de 1936, el Dr. Giral sentía profunda repugnancia por la adopción de medidas expeditivas, aun reconociendo que la realidad nacional exigía la aplicación ineludible de aquéllas. Por ello no es reprochable que en el ámbito de la administración de justicia, por su significación y sensibilidad, las cautelas fuesen aun mayores. Para superar tal laguna legislativa que el conflicto civil había evidenciado, se imponía legislar de modo especial, que bien podía aprobarse merced a lo previsto en los artículos 61 y 76 d) de la Constitución. A la postre, la fuerza de los hechos hizo inexcusable la adopción de medidas excepcionales ${ }^{18}$.

Pero sin duda, es en el encauzamiento institucional de la justicia popular embrionaria donde la actuación legislativa del gobierno tuvo su mayor mérito. Se configuraron con el carácter de especiales de la jurisdicción ordinaria, refiriéndose a ésta con el calificativo de civil para reafirmar la competencia sin confusiones con la propia de los tribunales militares y tenía como objetivo subyacente frenar las intervenciones y organizaciones que actuaban sin control alguno en asesinatos y ejecuciones arbitrarias, aplicando lo que el profesor Alba definió como una «justicia por consenso ${ }^{19}$, consensuada porque durante las primeras semanas era aceptada por el grueso de la población y por ello actuó con total libertad e impunidad. La masa veía en esos paseos, registros, detenciones y requisas unos actos de «justicia» verdadera y enraizada de forma auténtica con el pueblo ${ }^{20}$, habida cuenta de que la confianza en la justicia institucional había desaparecido, identificándola

17 «El país exige la aplicación de una justicia reparadora, y que no escapen de ella los causantes de la pavorosa tragedia que ha llevado el dolor a tantos hogares honrados» (El Pueblo, 29 de julio de 1936); «¡Ojo por ojo y diente por diente! (...) Nada de clemencia para los militares fascistas. El pueblo debe exigir justicia rápida, ejemplar. Y si no se la dan, tomársela por su mano.» (Solidaridad Obrera, 24 y 25 de julio de 1936); «porque la legalidad orilla muchas cosas y para obrar pide tanto, tanto, que las más de las veces no aparece para decidir ese por tantos conceptos relativo resorte justiciero" (Fragua Social, 22 de agosto de 1936) o la serie de premonitorios artículos publicados entre los días 19 y 26 de agosto de 1936 en Solidaridad Obrera y firmados con el seudónimo Juan Defensor, en los que se trazaron las líneas directrices de los que a juicio de los cenetistas debía ser la justicia popular.

18 RODRÍGUEZ OLAZÁBAL, J.: op. cit., p. 34.

19 ALBA, V.: «De los Tribunales Populares al Tribunal Especial» en Justicia en Guerra. Jornadas sobre la Administración de Justicia durante la Guerra Civil Española: Instituciones y fuentes documentales, Ministerio de Cultura, Madrid, 1990.

20 Como señala CERVERA, J.: Madrid en guerra. La ciudad clandestina 1936-1939, Alianza Editorial, Madrid, 1998, p. 57, incluso sobre algunas de las víctimas de estos crímenes en Madrid, se hallaron notas manuscritas que expresaban estas ideas y que eran una suerte de «sentencias» por las que se justificaba lo que no era más que un vil asesinato. Son ilustrativos los siguientes ejemplos: «Este por fascista. A (sic) disparado cuando pasaba la aviación fascista. Justicia del pueblo»; «Llego (sic) la hora de la justicia del pueblo que es severa pero justa. Que no quede ni un fascista vivo. Este es uno de ellos. Viva el pueblo revolucionario». 
como patrimonio de los poderosos. No obstante la loable pretensión gubernativa de dotar de una apariencia legal a esta siniestra concepción de la justicia, por lo menos hasta enero de 1937 se siguió produciendo ejecuciones arbitrarias ${ }^{21}$.

Analizado el panorama jurisdiccional en el otoño de 1936, pasemos a continuación a examinar su intervención en las decisiones que afectaron a las reservas de oro.

\section{MARIANO GRANADOS, O LA PERSONIFICACIÓN DEL PODER JUDICIAL EN EL POLVORÍN DE LA ALGAMECA}

Se impone, con carácter previo, ponderar cuál y cómo debiera haber sido, con arreglo a la Constitución y a las normas rituales de aplicación, la intervención del poder judicial en la decisión gubernativa de trasladar al extranjero las reservas de oro del Banco de España. Debe indicarse prima facie que nos encontramos ante una decisión que entra de lleno en la esfera de la plena discrecionalidad del Ejecutivo, debiendo catalogarse de decisión puramente política y basada en legítimos criterios de oportunidad en el marco de la legalidad vigente, lo que ya excluye al poder judicial de cualquier rol revisor previo de la decisión. En este sentido, resulta a estas alturas incontrovertible ${ }^{22}$ que la única vía de financiación para el aprovisionamiento armamentístico de la República en aquella coyuntura política era constituir una cuenta garantizada en oro en el extranjero, sobre la que cargar los gastos de campaña en que incurriera el gobierno republicano en defensa de la legalidad subvertida. Recuérdese que desde de 1888, con la llamada Ley Santamaría de Paredes, que era la vigente en $1936^{23}$, se transformó la jurisdicción de retenida en delegada, siendo el primer paso hacia lo que poco tiempo después

21 En septiembre de 1936, el Tribunal Especial de Madrid, comunicó al gobierno la condena a muerte al que fue ministro de gobernación del gobierno Lerroux, Rafael Salazar Alonso; el gobierno decidió conmutar la condena, pero el presidente del Tribunal, Mariano Gómez González (presidente interino en ese momento del Tribunal Supremo), informó al gobierno que el tribunal se amotinaría con la conmutación, dimitiría y que la consecuencia de esto sería que la ejecución se llevaría a cabo de todos modos y el gobierno perdería hasta la apariencia de autoridad; en vista de esto, se decidió no conmutar (BOLLOTEN, B.: La revolución española (sus orígenes, la izquierda y la lucha por el poder durante la guerra civil 1936-1939). Grijalbo, Barcelona 1980. Otro ejemplo paradigmático de esta situación fueron los acontecimientos acaecidos el día 10 de septiembre de 1936, fecha de señalamiento de la vista contra los jefes y oficiales del regimiento de Caballería de guarnición de Valencia, en cuya víspera, D. Blas López Fandos, a la sazón secretario particular del presidente de la audiencia territorial, D. José Rodríguez Olozábal, le dijo a éste: «-Me aseguran que mañana no se celebrará el juicio contra los jefes y oficiales de Caballería, porque el Comité de Salud Pública ha decidido ejecutarlos a todos esta noche». Si bien esa misma noche y gracias a las rápidas gestiones del propio Rodríguez Olazábal y de algunos jurados, pudieron salvarse a 18 de los militares encausados, para dos de ellos fue demasiado tarde y fueron «sacados» de las prisiones en donde estaban recluidos, celebrándose al día siguiente la vista contra los restantes, de los cuales siete fueron condenados a la pena de muerte. Así, y gracias a la institucionalización de la justicia revolucionaria, se salvaron de una muerte segura a manos del criminal Comité de Salud Pública once sublevados. RODRÍGUEZ OLAZÁBAL, J. op. cit., p. 49.

22 VIÑAS, op. cit., p. 388.

${ }^{23}$ No obstante la modificación que introdujo la Ley de 5 de abril de 1904 (Ley Maura), que arrancó definitivamente la jurisdicción del Consejo de Estado para confiarla a una Sala especial del Tribunal Su- 
sería la plena judicialización en el control de la Administración. Si a ello le unimos la previsión que la Constitución de 9 de diciembre de 1931 contemplaba en su artículo 101:

La ley establecerá recursos contra la ilegalidad de los actos o disposiciones emanadas de la Administración en el ejercicio de su potestad reglamentaria, y contra los actos discrecionales de la misma, constitutivos de exceso o desviación de poder.

hemos de concluir que la intervención del poder judicial en relación con las disposiciones habilitantes para proceder al traslado y custodia del oro debieran haberse producido siempre y en todo acaso a posteriori, una vez que los Decretos hubieren sido, en su caso, impugnados. Ahora bien, aquí concurre la paradoja de la forma reservada de promulgación, lo que impedía el conocimiento de los mismos y, por ende, limitaba drásticamente su publicidad como presupuesto de recurribilidad. No obstante, esa tara en su inimpugnabilidad venía salvada por la obligación del Gobierno de dar cuenta del Decreto de 13 de septiembre de 1936 a las Cortes, lo que finalmente nunca se verificó, más allá de conjeturas que fijarían el 29 de abril de 1938 como fecha de comunicación del Gobierno a las Cortes de los acuerdos reservados.

Y ahí precisamente es donde, a nuestro juicio, radica el principal reproche que puede dirigirse contra el entramado normativo que sostuvo la decisión del traslado. Se podrá argüir, como por cierto lo hacen todas las disposiciones citadas, que la situación de anormalidad generada por la sedición de los militares rebeldes imponía la reserva de la disposición normativa, lo que en modo alguno se discute aquí. La no publicación de una disposición legislativa, por razones suficientemente motivadas, no la priva en absoluto su eficacia aplicativa. Lo que resulta reprochable al Ejecutivo de Largo Caballero es sin embargo la inacción en el sometimiento del decreto para su fiscalización por las Cortes, como así lo preveía la propia pieza legislativa, por cierto. Y es que, recuérdese, que hasta el 24 de enero de 1939, en la zona leal a la República no se declaró el Estado de Guerra, resultando, por ende, plenamente aplicable los derechos y garantías previstas constitucionalmente, entre las que constaba, desde luego, la obligación de dar cuenta en sede de la soberanía nacional de los Decretos, reservados o no, aprobados por el Gobierno.

No es descartable por tanto inferir que, dada la certeza del Gobierno, o al menos de los miembros que directamente estaban vinculados con la acción, a saber, su presidente, Largo Caballero, y los ministros de Hacienda y de Marina y Aire, Negrín y Prieto, respectivamente, de que no se iba a someter a las Cortes los decretos promulgados de manera reservada, se decidiera formar una comisión tripartita en la que estuviese representados el poder ejecutivo, el legislativo y, quizá

premo, compuesta de magistrados sometidos al estatuto de la carrera judicial, pero de procedencia mixta (judicial y administrativa). 
con algún cargo de conciencia de índole jurídico-procesal, el judicial, que supervisarse el traslado efectivo del oro en su última fase, es decir desde la base de La Algameca hasta los mercantes ${ }^{24}$ que finalmente lo transportaran al puerto ucraniano de Odessa. Nótese a este respecto que esta triple representación no estuvo presente ni en la extracción del metal desde la cámara acorazada de la plaza de Cibeles la madrugada del 14 de septiembre, que fue dirigida por el Director General del Tesoro, Méndez Aspe ${ }^{25}$, ni en el posterior traslado del oro vía férrea desde la estación de Mediodía hasta la de Cartagena, que en todo momento fue custodiado por la Brigada Motorizada del PSOE. Por ello, aunque coincidimos plenamente con el profesor Miralles Sangro, que en su imprescindible y referencial trabajo antes citado sobre el que era en ese momento presidente del Tribunal Supremo, Mariano Gómez ${ }^{26}$, califica como acertada y aguda la decisión política de vincular los tres poderes con la operación del oro, entendemos sin embargo, que detrás de ese recurso político de innegable perspicacia, latía un afán convalidante de una irregularidad jurídica incuestionable, y en caso alguno justificable por mor de la guerra, no en vano hasta el 1 de febrero de 1939, en el Castillo de San Fernando de Figueras, se produjeron actos plenarios de las legítimas Cortes republicanas.

¿Y quien representó al poder judicial en semejante coyuntura? Pues junto con al doctor Giral, que como ministro sin cartera representaba al Ejecutivo $-\mathrm{y}$, porqué no decirlo, también a la Jefatura del Estado, lo que impide razonablemente argüir la malévolamente extendida ignorancia de Azaña de esta operación-y Luis Fernández Clérigo, vicepresidente primero de las Cortes, en representación del Legislativo y delegado del presidente Martínez Barrio, el tercer poder tuvo en la figura del presidente de la Sala Quinta del Tribunal Supremo, Mariano Granados de Aguirre, a su apoderado.

Como señalábamos al inicio de estas páginas, Mariano Granados simboliza de manera arquetípica al republicano convencido, cuyas convicciones políticas en ningún momento mermaron, más al contrario, exacerbaron su sentimiento español. Hay al hilo de esto último un episodio ${ }^{27}$ absolutamente hilarante de nuestro protagonista, en 1919 y recién licenciado en Derecho, que pone de manifiesto ese sentimiento de españolidad perfectamente compatible con el republicanismo militante de un soriano nacido, por cierto, en una acomodada familia de la burguesía local, íntimo amigo de Gerardo Diego ${ }^{28}$ y siendo su padre el insigne Mariano Granados Campos, fundador de la Caja de Ahorros y Préstamos de la Provincia de Soria, a quien está dedicada la plaza homónima y que goza de estatua en el Parque de la Dehesa. En síntesis, Granados se desplaza ese año a Córdoba a apoyar

24 Jruso, Neva, Kim, y Volgores.

25 Auxiliado por el capitán de Carabineros Julio López Masegosa, medio centenar de metalúrgicos y cerrajeros y un grupo de empleados de banca pertenecientes al Sindicato de Madrid.

26 Al servicio de la Justicia ... p. 141.

27 VEGA RUIZ, A.: «Mariano Granados, una figura olvidada a reivindicar» ABANCO, n 33.

28 Fue Granados quien llevó en su viejo Ford al poeta cántabro al Monasterio de Silos, donde escribió el legendario soneto dedicado a su ciprés. 
las candidaturas republicanas y a su paisano Hilario Ayuso, teniendo la oportunidad de conocer durante esos día al periodista y anarquista Mauro Bajatierra Morán, con quien llegó hasta el Campo de Gibraltar y la Línea para pronunciar algunos discursos. Fue entonces cuando el soriano de apenas veintitrés años caminó hasta la verja del Peñón y ante un sorprendido bobby de guardia le dijo:

«En nombre del pueblo español, declaro la guerra a Inglaterra. Queda establecido el estado de sitio de Gibraltar. Good Morning"

En Córdoba, días después, fue detenido por la Guardia Civil y encarcelado en Aguilar de la Frontera, de donde logró salir merced a la intercesión de su antiguo profesor de Derecho Internacional y Ministro de Gobernación por entonces, Antonio Goicoechea y Cosculluela. Desde 1923 frecuenta, junto con intelectuales y escritores como Gómez de la Serna, Paco Vighi, Edgar Neville, José Tudela o Antonio Botín la tertulia diaria organizada por Ortega y Gasset en la redacción de la Revista de Occidente, dejando escritos durante esos años obra poética como Las Novias, (Madrid 1926), y prosas como Retablo (Madrid, 1926) o Martingala (Madrid, 1928)

La peripecia profesional de Granados puede decirse con razón que comenzó en Córdoba y continuó en esa misma ciudad, pues ocho años después, en mayo de 1927 obtuvo plaza en la ciudad califal como Abogado Fiscal interino, de donde se trasladará como titular a la Audiencia de Tarragona dos meses después. Poco antes de la venida de su anhelada República, en abril de 1930 asciende a teniente fiscal con destino en la Territorial de Soria. Su primer destino en la ya instaurada Segunda República fue precisamente en la Audiencia Territorial de Madrid, en junio de 1931, siendo nombrado en septiembre de 1932 Comisario Inspector de Juzgados y Tribunales con categoría de magistrado del Tribunal Supremo. Categoría que alcanzó de derecho el 28 de enero de 1933, siendo adscrito en principio a la Sala Segunda, de la que fue trasladado posteriormente a la Quinta. Precisamente su responsabilidad en la Inspección le obligó a intervenir directamente en la revisión y fiscalización de los sumarios de Casas Viejas, en donde no dudó en informar al Presiente de la República de las numerosas irregularidades detectadas tanto en la actuación de la Guardia Civil como del fiscal de Cádiz ${ }^{29}$.En abril de 1936 fue nombrado vocal y vicepresidente de la Comisión Superior de Protección de Menores, alcanzando en agosto y ya con la guerra lanzada, la presidencia de la Sala Quinta —que conocía de lo social-. En el mes de septiembre y en cumplimiento de lo previsto por el Decreto de 21 de agosto, fue nombrado presidente de la Junta de Inspección de Tribunales de Alicante.

Así llegamos a la tarde del 22 de octubre de 1936, en la que la referida representación institucional partió desde Alicante hacia Cartagena, para desde allí des-

29 AZAÑA, M.: «Diarios completos. Monarquía, República, Guerra Civil», Crítica, Barcelona, 2000, p. 726 y 744 . 
plazarse hasta la base naval de La Algameca, donde bajo la supervisión de Prieto, Negrín y del Director General del Tesoro, Méndez Aspe, con el auxilio del jefe de la base, Antonio Ruiz, que puso a disposición de las labores de estiba a sesenta hombres de la guarnición, bajo las órdenes del oficial Ramírez de Togores, comenzaron los trabajos, que fueron coordinados con los mercantes soviéticos a través de la omnipresente figura de Alexander M. Orlov, y el agregado naval soviético, Nikolái Gerásimovich Kuznetsov.

En cuanto a la intervención directa durantes esas horas de los tres representantes de los poderes constitucionales, es razonable pensar que tanto Fernández Clérigo como Granados Aguirre, actuando en nombre y representación de Martínez Barrio y Mariano Gómez, como apoderados del legislativo y del judicial, respectivamente, tuvieran una participación meramente testimonial, muy en la línea de investir de cierta solemnidad institucional una operación ciertamente delicada y, como ya se ha razonado, al menos discutible desde el punto de vista de su rigor jurídico. Capítulo aparte merece la intervención en ese instante de Giral, no tanto por ser representante del ejecutivo -e insistimos, ojos y oídos de su entrañable Manuel Azaña-, sino porque, recuérdese, fue el doctor en persona quien elaboró un detallado informe de la idoneidad de las instalaciones, en el que se pormenorizaba sobre la instalación, vigilancia, armamento e incluso menaje ${ }^{30}$.

La carga de la valiosa mercancía culminó el 25 de octubre, acompañándola a bordo de los mercantes soviéticos los funcionarios del Banco de España José Velasco Sierra, José González Álvarez, Arturo Candela Marquestauit y Abelardo Padín ${ }^{31}$. El convoy arribó a Odessa el 2 de noviembre, llegando a Moscú por vía férrea el día 5, justo un día antes de que se desencadenara la Batalla de Madrid. Al día siguiente, a partir de las tres de la madrugada y con la presencia del desinformado $^{32}$ embajador Marcelino Pascua, se empezó a trasladar las sacas y las cajas desde la estación Kiev hasta el Gohkran, extendiéndose un primer protocolo de recepción el 7 de noviembre, y otro el día 10, pues el cargamento del cuarto mercante, llegó con retraso debido a una avería en alta mar.

Precisamente el día 6 de noviembre el Gobierno de Largo Caballero abandonaba precipitadamente la capital de España con destino a Valencia, y en esa mudanza no fue menor la intervención, otra vez, de Mariano Granados. En efecto, el traslado del Gobierno a Valencia acarreó, consecuentemente, el trasiego tam-

\footnotetext{
30 «Se necesitan literas para unos cien hombres (...) una cocina de hierro (..) Es necesario que los carabineros NO VAYAN CON SUS FAMILIAS...» VIÑAS, op. cit., p. 477 y ss.

31 Estos cuatro funcionarios del Banco de España (que en las comunicaciones diplomáticas entre la embajada española y el gobierno de Largo fueron designados como «Valentín», «Garrido», "Cándido» y «Pablo», respectivamente), quedáronse en la capital soviética hasta la culminación del recuento y recepción del oro, que se verificó el 24 de enero de 1937. Su estancia en Moscú fue sufragada con fondos habilitados por la legación española ante el Kremlin, con Pascua a la cabeza, pues en su afán de secretismo, el gobierno español no había previsto partidas ni instrucciones precisas para el embajador Pascua en relación con la inminente llegada del cargamento y de los empleados públicos que lo acompañaron

32 VIÑAS, op. cit., Anexo. Doc. № 1.
} 
bién del Tribunal Supremo que, junto con el Ministerio de Justicia se instaló provisionalmente en el edificio de la audiencia territorial de la capital levantina, para ubicarse después en un inmueble sito en la plaza del Poeta Liern no 7. La documentación trasladada fue tan sólo la imprescindible para poder seguir funcionando y la que estaba en curso de trámite. La mayor parte de ella fue enviada el día 28 de noviembre de 1936 y entre los legajos más relevantes destacan los 1.100 expedientes informativos de funcionarios judiciales, las fichas que la inspección de tribunales poseía sobre los miembros de la carrera judicial, carpetas de indultos y cuestiones gubernamentales, los expedientes relativos a la demarcación judicial de las diferentes provincias y los libros de votos reservados de las Salas. En este tránsito tuvo un papel cualificado el magistrado de Buen Lozano, auxiliado por el citado Granados, quien, el 11 de diciembre, retiraba del archivo del Palacio de Justicia la documentación más sensible y que a fecha de hoy sigue en paradero desconocido: el Libro de Actas de Sala de Gobierno abierto el año 1935, el Libro de Actas del Pleno y el Libro de votos reservados del mismo Tribunal. Asimismo, y en marzo de 1937, por su valor simbólico el citado magistrado trasladó a Valencia el gran collar de la justicia, collar de diario de uso presidencial ${ }^{33}$ y la placa de magistrado del Tribunal Supremo de uso presidencial ${ }^{34}$.

Debe subrayarse la eficiencia del traslado, teniendo en cuenta la magnitud de la mudanza y el dato de que el día 11 del propio mes de noviembre se celebró la primera reunión bajo el nombre de «comisión de funcionarios de la administración de justicia», presidida por Fernando Abarrategui, presidente de la Sala Segunda, ya que tanto Mariano Gómez como Demófilo de Buen, continuaban en Madrid ultimado las gestiones del traslado y la organización de la trama judicial que debía quedar en la capital. La citada comisión se convirtió inmediatamente en verdadero Tribunal en Pleno al designarse una Sala de Gobierno Provisional compuesta por el propio Abarrategui Pontes (Segunda), Javier Elola (Tercera), Alberto de Paz (Cuarta) y Mariano Granados (Quinta), y los magistrados Aragonés Champín, Fernández Gordillo, Uribarri Mateos, Valentín Torrejón, Torres Roldán, Carazony de la Rosa, Pascual Leone, Berenguer de las Cagigas y González Barrón, y un secretario de Gobierno en la figura de Manuel Betés Bruzos.

El día 28 de octubre de 1937, el ya presidente del Consejo Juan Negrín, anuncia de nuevo el traslado del gobierno a Barcelona, y con él, el del grueso de la administración. De esta forma se inicia lo que será el último viaje del Tribunal Supremo constitucionalmente reconocido ${ }^{35}$, cuyas últimas sentencias fueron dictadas

${ }^{33}$ Sobre la peripecia del Gran Collar, vid. MIRALLES SANGRO, op. cit., pp. 178,180,188 y 190.

${ }^{34}$ MARZAL RODRÍGUEZ, P.: op. cit., p. 174.

${ }_{35}$ Mudanza que resultó mucho más complicada habida cuenta de la situación bélica reinante en el momento. Es ilustrativo de ello el requerimiento que a fecha de 28 de enero de 1939 realizó el presidente del Tribunal Supremo al Sindicato Único del Transporte para que facilitara los medios necesarios para el transporte del personal administrativo y la documentación a desde la capital del Turia hasta Barcelona y la contestación dada por el Sindicato: «Acusamos recibo de su atento oficio de 28 de los corrientes, y nos complace recordarles que el servicio por ustedes solicitado, no fue prestado a su debido tiempo a causa del temporal de nieve que hemos padecido. Posteriormente, las actividades bélicas de nuestro Ejército, 
en la ciudad condal pocos días antes de la entrada de las tropas del general Yagüe ${ }^{36}$.

Mariano Granados logra alcanzar la frontera francesa a finales de enero de 1939, siendo el único soriano que acudió al entierro de Antonio Machado, quien había sido su profesor de Instituto en Soria, a quien dedicó ese 23 de febrero los siguientes versos:

\section{ANTE LA TUMBA DE MACHADO}

"Adiós, maestro, adiós. Adiós te digo.

Mi corazón es y será tu templo.

Fuiste maestro, fraternal amigo,

y sobre todo luminoso ejemplo.

Aquí te dejo, Antonio, en tierra extraña,

lejos de tu venero de armonía,

fuera de nuestra Soria, nuestra España,

bajo tierra que no es tuya ni mía.

Ni la vieja Ciudad, ni los caminos

aromados de espliegos y romero,

volverán a anudar nuestros destinos

que tu mano anudó en el alto Duero.

Niño aún, casi, casi adolescente,

me tendíste tu mano, y a ella asido,

tu dolorosa senda he proseguido,

y fue mi luz, la luz de tu alta frente.

Hace treinta y dos años, mi memoria

que es fiel, guarda aquel primer tributo

que te rendí en Soria, nuestra Soria,

dentro del aula dos de su Instituto.

En pos de tí, y de tu sombra en pos,

ha absorbido nuestro material. Y ahora que este material está disponible, carecemos de combustible». (MARZAL RODRÍGUEZ, P.: op. cit., p. 174.)

${ }^{36}$ La última sentencia de la Sala de lo Civil fue de fecha 17 de diciembre de 1938, formando Sala los magistrados de Buen Lozano, Castán Tobeñas y Fentanes Portela. De la Sala de lo Criminal, la de 23 de julio de 1938, firmada por los Sres. Moreno Fernández de Rodas, Puebla Aguirre, Muñoz Lorente, Ballesteros Álava y Abarrategui Pontes. Por último, la Sala de lo Contencioso-Administrativo del Tribunal Supremo tuvo el trágico honor de pronunciar la última sentencia de éste órgano, de fecha 28 de diciembre, prácticamente un mes antes de la caída de Barcelona, siendo sus autores los magistrados Fernández Orbeta, Pascual Leone y Dionisio Ferrer. 
llego a verte emprender tu último viaje

cual quisiste, ligero de equipaje,

pero no solo. Yo te acompaño. Adiós.»

Granados se instalará, después de haber sido oportunamente separado definitivamente del servicio y dado de baja del Cuerpo por las autoridades franquistas, junto con otros tantos eximios juristas españoles —Alcalá Zamora, Joaquín Rodríguez, Luis Recasens, Ruiz-Funes, de Buen Lozano, Sánchez Román o Victoria Kent- en el hospitalario México de Lázaro Cárdenas, no sin volver a su querida Soria a principios de los años setenta, donde durante unas semanas mantuvo abierta tertulia en la librería familiar de la Avenida de Navarra.

\section{BIBLIOGRAFÍA}

AlbA, V.: «De los Tribunales Populares al Tribunal Especial» en «Justicia en Guerra. Jornadas sobre la Administración de Justicia durante la Guerra Civil Española: Instituciones y fuentes documentales», Madrid, Ministerio de Cultura, 1990.

Azaña, M.: Diarios completos. Monarquía, República, Guerra Civil, Barcelona, Crítica, 2000.

BeneIto LloRIS, Á.: El Hospital Sueco Noruego de Alcoi durante la Guerra Civil Española. Alcoy, Alfa Ediciones Gráficas, 2004.

Bolloten, B.: La revolución española (sus orígenes, la izquierda y la lucha por el poder durante la guerra civil 1936-1939). Barcelona, Grijalbo, 1980.

Cancio Fernández, R.C.: Guerra civil y tribunales: de los jurados populares a la justicia franquista (1936-1939). Cáceres, Universidad de Extremadura, 2007.

Cervera, J.: Madrid en guerra. La ciudad clandestina 1936-1939. Madrid, Alianza Editorial 1998.

Granados de Aguirre, M.: Tránsito. Poesías. México, D.F., Castilla, 1944.

Howson, G.: Armas para España. La historia no contada de la guerra civil española. Barcelona, Península, 2000.

KoWALSKY, D.: La Unión Soviética y la guerra civil española: una revisión crítica. Barcelona, Crítica, 2003.

López Romero, L: Joaquín Pérez Salas: (segunda época 1937-1938). Pozoblanco, Ayuntamiento de Pozoblanco, 2006.

Martín Aceña, P.: El Oro de Moscú y el Oro de Berlín. Madrid, Taurus, 2001.

MARZAL Rodríguez, P.: «La alta magistratura en el reciente constitucionalismo español: paralelismos y discrepancias», en Constitución española. XXV Aniversario, Valencia, Generalitat Valenciana, 2004.

MiRalles, R.: Juan Negrín: la República en guerra. Madrid, Temas de Hoy, 2003.

Miralles Sangro, P. P.: Al servicio de la Justicia y de la República. Mariano Gómez (18831951) Presidente del Tribunal Supremo. Madrid, Dilex, 2010. 
Roso, J. A.: Vicente Rojo. Retrato de un general republicano. Barcelona, Tusquets, 2006.

SÁNCHEZ RECIO, G.: «Justicia ordinaria y Justicia popular durante la guerra civil» en Justicia en Guerra. Jornadas sobre la Administración de Justicia durante la Guerra Civil Española: Instituciones y fuentes documentales. Madrid, Ministerio de Cultura, 1990.

Vega RuIz, A.: «Mariano Granados, una figura olvidada a reivindicar», ABANCO, no 33.

VIÑAS, Á.:

- El oro de Moscú. Barcelona, Grijalbo, 1979

- La soledad de la República: el abandono de las democracias y el viraje hacia la Unión Soviética. Barcelona, Barcelona, Crítica, 2006.

- El escudo de la República. El oro de España, la apuesta soviética y los hechos de mayo de 1937. Barcelona, Crítica, 2007.

ZugazagoitiA, J.: Guerra y vicisitudes de los españoles. Barcelona, Tusquets, 2001.

\section{APÉNDICE GRÁFICO}

1. Mariano Granados

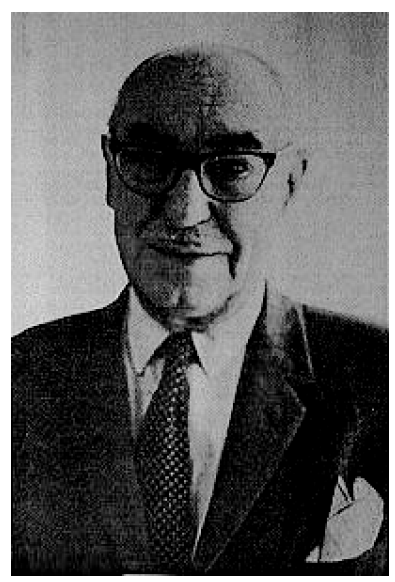


2. Inauguración de la cámara acorazada del Banco de España (1936)

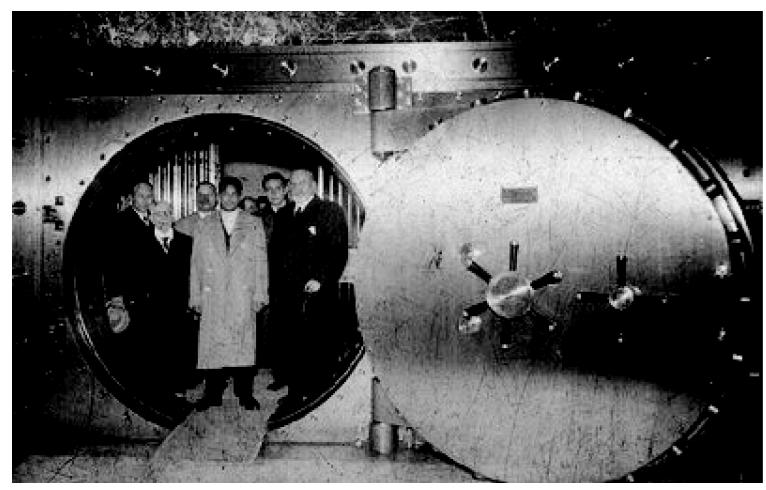

3. Caricatura de Mariano Granados

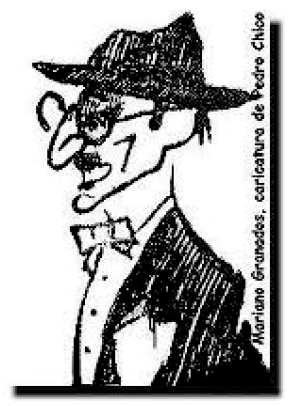

4. Juan Negrín e Indalecio Prieto, ministros de Hacienda y Marina y Aire en octubre de 1936

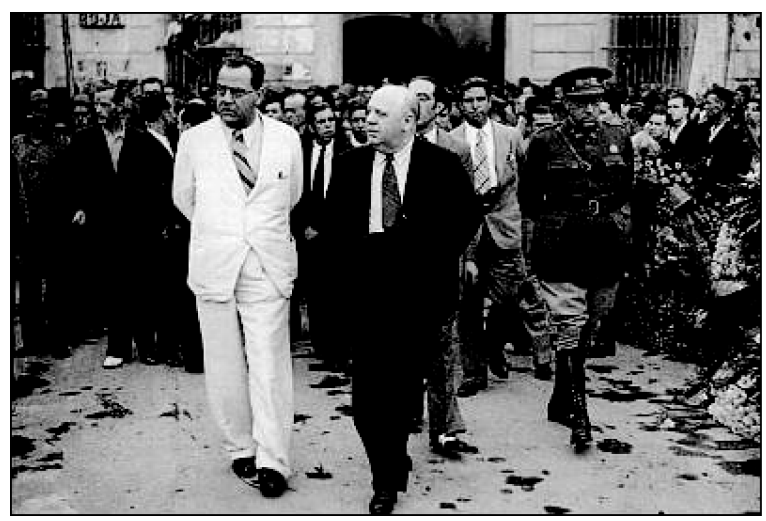


5. Nikolái Gerásimovich Kuznetsov

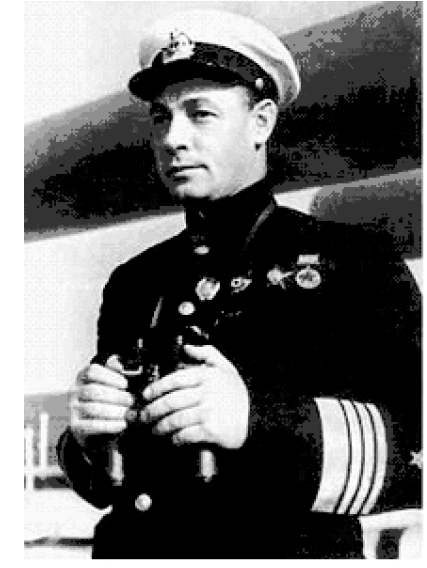

6. Alexander M. Orlov

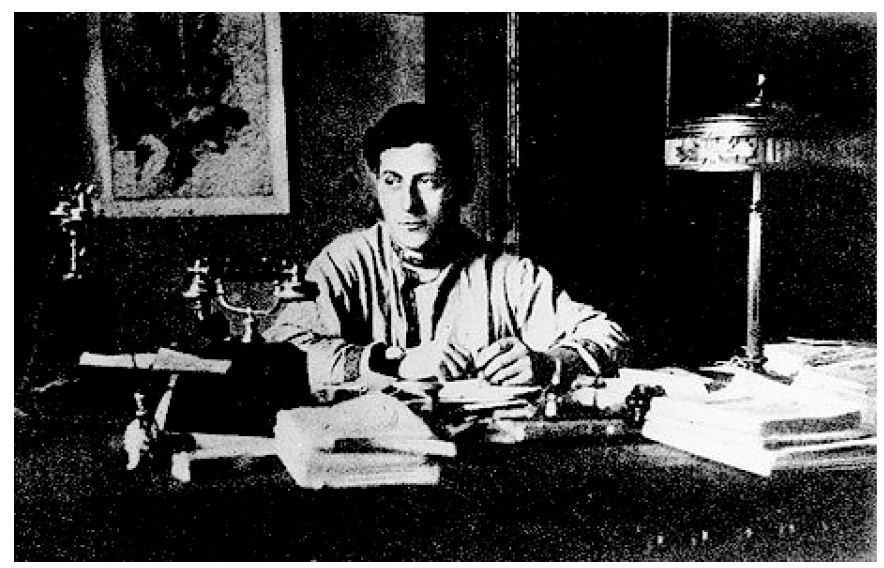

7. Túnel de La Algameca, destinado al almacenamiento de minas, y que acogió las cajas del oro del Banco de España

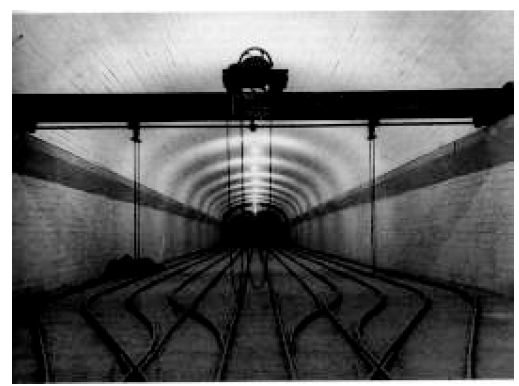


Mariano Granados de Aguirre y la cobertura legal del traslado del «Oro de Moscú»

8. Base Naval de La Algameca, Cartagena

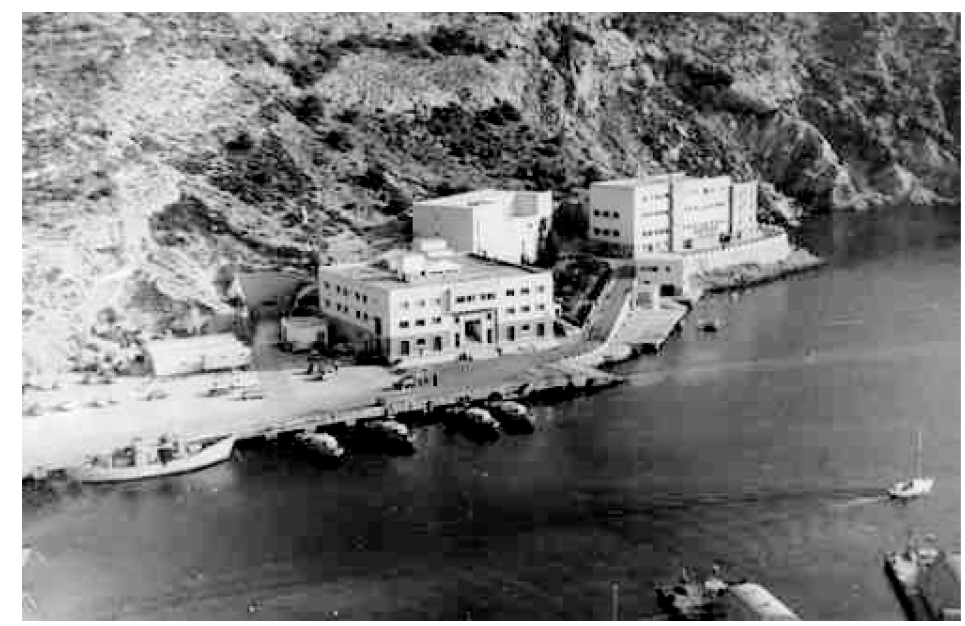


